\title{
Performance evaluation for sustainability of wind energy project using improved multi-criteria decision-making method
}

\author{
Jiahui $\mathrm{WU}^{1}{ }^{\mathbb{1}}$, Haiyun WANG ${ }^{1}$, Weiqing $\mathrm{WANG}^{1}$, Qiang ZHANG $^{2}$
}

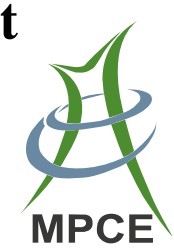

\begin{abstract}
Wind power can be an efficient way to alleviate energy shortage and environmental pollution, and to realize sustainable development in terms of energy generation. The sustainability assessment of a wind project among its alternatives is a complex task that cannot be solely simplified to environmental or economic feasibility. It requires the consideration of its technological and social aspects as well as other circumstances. This paper proposes a new method for selecting the most sustainable wind projects. The method is based on multi-criteria decision-making techniques. The analytic hierarchy process and entropy weight method are combined to determine the weights of evaluation indexes, and an innovative index-weight optimization method based on the Lagrange conditional extremum algorithm. The fuzzy technique for order preference by similarity to the ideal solution is applied to rank wind project alternatives considering functionality and
\end{abstract}

CrossCheck date: 15 January 2019

Received: 28 December 2018/ Accepted: 15 January 2019/Published online: 9 April 2019

(C) The Author(s) 2019

$\triangle$ Jiahui WU

wjha29@sina.com

Haiyun WANG

whyxju1220@163.com

Weiqing WANG

wwq59@sina.com

Qiang ZHANG

244617740@qq.com

1 College of Electrical Engineering, Xinjiang University, Urumqi 830047, China

2 State Grid Xinjiang Electric Power Research Institute, Urumqi 830011, China proportionality of the system. Moreover, the sensitive analysis is applied to verify the robustness of the proposed method. The applicability of the method is demonstrated on a case study from China, where three main wind projects are analytically compared and ranked. The results indicated that the sustainable level of calculated wind power can provide a reference point for the planning and operation of the wind project. The results show that the proposed method is of both theoretical significance and practical application in engineering.

Keywords Analytic hierarchy process, Comprehensive evaluation index, Entropy method, Fuzzy technique, Order preference, Wind power sustainability level

\section{Introduction}

The rapid development of the world economy brings potential problems of energy and environment such as global environmental deterioration, shortage of traditional energy resources, and climate change. The growing demand and use of coal, oil, natural gas, and other traditional energy sources, which are unsustainable energies, have generated concerns regarding serious environmental pollution. Given the negative externalities of traditional energy generation activities, the construction and operation of wind energy represent a strategic method to realize sustainable development. Furthermore, wind power would be an important platform for energy supply and plays a leading role in de-carbonization in the near future. However, generating power on a mainstream basis assumes new responsibilities such as the insurance of a reliable and costeffective functioning of the overall energy system and its contribution to energy security. This becomes problematic 
because wind power, by nature, is characterized by stochastic fluctuation, which affects the stability of the original power grid and restricts the sustainable development of the renewable energy [1]. Other challenges have been linked to the feed-in tariff (FIT), which is an increasing burden on Chinese government [2] due to the rapid development of wind power. As a result, the development of funding solutions to finance the FIT has increased, thereby resulting in pressure on the renewable industry to lower its costs. A combination of all these challenges may result in a waste of wind resources, an economic deficit on wind projects, and may hinder the sustainable development of wind energy.

"Sustainability" can be described as the endurance of systems and processes. The organizing principle for sustainability is sustainable development, which includes four pillars: technological development, economic growth, social development and environmental protection. Identifying the most sustainable wind project can minimize the use of traditional coal resources, alleviate environmental burdens, and simultaneously contribute to the local economy and increase employment. Currently, studies related to the sustainability of renewable energy resources (RES) to evaluate the power grid have been conducted. Reference [3] evaluated clean energy options for Algerian by applying 13 sub-criteria, of which solar photovoltaic was ranked as the first, followed by wind, biomass, geothermal, and lastly hydropower. Reference [4] provided an empirical evaluation of FIT and the renewable portfolio standard policies that were applied to onshore wind power, of which only FIT policies were suggested to exhibit significant impacts on the installed capacity. The aforementioned studies examined the sustainability of different kinds of renewables, or the partial sustainable characters of wind energy such as wind energy policies. The comprehensive evaluation of sustainable wind energy levels has not been reported. Many wind projects face related difficulties such as ecological harm, construction delays, and economic unprofitability. To better manage these issues, wind projects must be evaluated with sustainability dimensions and structured approaches. The present study performed wellrounded research to measure the sustainability of wind projects in consideration of multiple aspects to serve as an important topic for the sustainable development of wind projects and to fulfill the current research gap.

This paper examines the sustainable performance of wind generation projects as a multi-criteria decision-making (MCDM) problem. The primary MCDM analysis step is the calculation of weights for the various indicators, which includes subjective weighting methods and objective weighting methods. Objective weighting methods emphasize the differences between indices, whereas subjective weighting methods can provide an absolute measure of importance. However, most studies only employ either subjective or objective methods to determine the weights. For example, a comprehensive assessment method that considers voltage and power losses was presented, wherein the weights were determined only by objective judgment [5]. In another case [6], only a subjective methodology combining the analytic hierarchy process (AHP) method and expert feedback was employed to evaluate different renewable energy options. In response to the limitations of subjective and objective weighting methods, both methods were ideally employed in proportion to their designated importance.

Under these circumstances, this paper aims to propose a sustainable level evaluation model for wind generation projects as a decision support tool for scholars and investors with the intention of integrating different sustainable wind project indexes in a multi-index system using the MCDM method. To address the limitations of subjective and objective weighting methods, this paper presents an index weighting optimization method that combines both subjective and objective weighting methods in proportion to their designated importance by using the Lagrange conditional extremum algorithm (LCEA). Lastly, the fuzzy technique for order preference by similarity to the ideal solution (TOPSIS) method is employed to provide a reasonable ranking of the results. This method fully employs existing information to enhance the objectivity of the ranking results.

\section{Establish index systems}

\subsection{Identification of evaluation indexes and hierarchy}

The selection of the most suitable assessment indexes and their scoring plays a vital role. Thus, the first step in the proposed method is to determine the indexes for the sustainable assessment of wind projects. The proposed model offered in the present study generates 16 sub-criteria in a three-layer structure that is subjected to expert validation, of which the hierarchical structure rationality of the selection criteria is validated as proposed in this paper. The structure of the model is presented in Fig. 1.

As shown in Fig. 1, the overall target is situated at the first level of the proposed hierarchy $A$. In the second level, the sub-target criteria are denoted as $\boldsymbol{P}_{1}, \boldsymbol{P}_{2}, \boldsymbol{P}_{3}, \boldsymbol{P}_{4}$, and $\boldsymbol{P}_{5}$. The indexes in the 3 rd level are listed as $X_{1}, X_{2}, \ldots, X_{16}$, where $\boldsymbol{P}_{1}=\left\{X_{1}, X_{2}, X_{3}, X_{4}\right\}, \boldsymbol{P}_{2}=\left\{X_{5}, X_{6}, X_{7}, X_{8}\right\}$, $\boldsymbol{P}_{3}=\left\{X_{9}, X_{10}\right\}, \boldsymbol{P}_{4}=\left\{X_{11}, X_{12}, X_{13}\right\}$, and $\boldsymbol{P}_{5}=\left\{X_{14}, X_{15}\right.$, $\left.X_{16}\right\}$. 


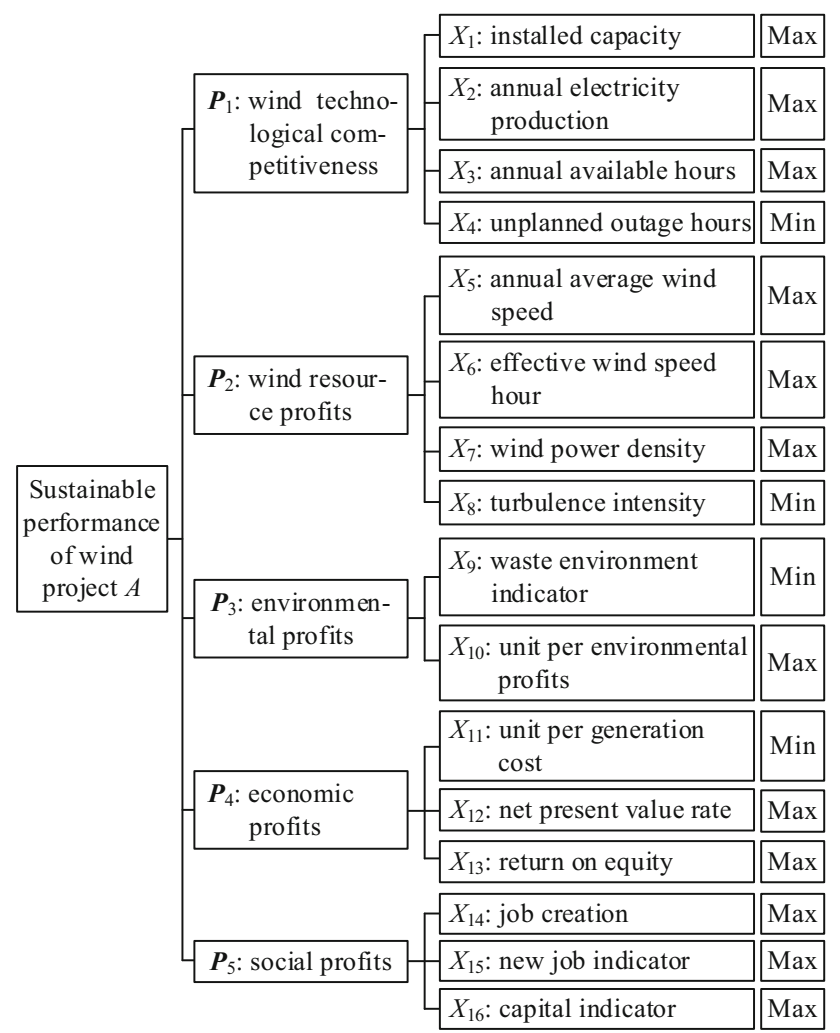

Fig. 1 Hierarchy of proposed assessment indexes

\subsection{Wind technological competitiveness}

Technology sophistication decides the efficiency of wind electricity generation and the stability level of wind operations [7]. Thus, the advances in wind generators can save manpower, operation time, and maintain a lower cost. For instance, the index of installed capacity means the electricity generating capacity and the index of annual electricity production decides the scale magnitude of wind farms. The larger the total installed capacity and the annual electricity production, the more competitive the wind project is. This sub-section introduces four main indexes, which can reflect the degree of technological advancement of different wind projects.

1) $X_{1}$ refers to the total installed capacity of wind farms.

2) $X_{2}$ refers to the wind power generated over a year, which can be calculated by:

$W=P_{\mathrm{m}} \times 8760$

where $P_{\mathrm{m}}$ is the total active power of wind farms.

3) $X_{3}$ measures the capacity hours of wind equipment under full load operating conditions for a certain period of time, which is defined as (2), and $P_{g e n}$ represents the generating capacity and $P_{i n s}$ is the installed capacity:
$X_{3}=\frac{P_{\text {gen }}}{P_{\text {ins }}}$

4) $X_{4}$ refers to the outage hours which may be caused by turbine faults, unnecessary repairs and maintenance, etc.

\subsection{Wind resource profits}

Unlike constructing a thermal power plant, new wind farms is greatly dependent on nature conditions of wind, in that the chosen terrain needs to have abundant wind resources [8]. For example, the location should have high wind power density and low turbulence intensity. The wind speed should be higher than $4.38 \mathrm{~m} / \mathrm{s}$ and effective wind speed hours should be longer than 2000 hours. Thus, only if the demand of large-scale centralized development of wind power in China is in accordance with its environment, can the wind power projects properly develop. The environmental indexes for the evaluation of wind project sustainability are summarized as follows.

1) $X_{5}$ refers to the average instantaneous wind speed over a year.

2) $X_{6}$ refers to the hours of speed higher than $3 \mathrm{~m} / \mathrm{s}$ over a year.

3) $X_{7}$ refers to the available resource of raw wind power, which can be calculated according to the following equation:

$X_{7}=\frac{1}{2} \rho v^{3}$

where $v$ is the wind speed and $\rho$ is the air density.

4) $X_{8}$ is crucial for wind turbine structure design and aerodynamic loads calculation. Besides the impact on power output, turbulence intensity imposes significant aerodynamic loads on wind turbines. Turbulence intensity is defined as the ratio of the standard deviation of wind speed $V_{\delta}$ to the mean wind speed of 10 minutes $\bar{V}_{10}$ :

$X_{8}=V_{\delta} / \bar{V}_{10}$

$V_{\delta}=\sqrt{\frac{1}{N} \sum_{i=1}^{N}\left(v_{i}-\bar{v}\right)^{2}}$

where $v_{i}$ is $i^{\text {th }}$ criteria group of wind speed sample; $\bar{v}$ is the mean wind speed; and $N$ is the total number of wind speed samples. The grading standard of the above indexes can be seen in Table 1. 
Table 1 Grading standard of wind resource index

\begin{tabular}{lllll}
\hline Wind environment index & $\begin{array}{l}\text { Annual mean wind } \\
\text { speed }(\mathrm{m} / \mathrm{s})\end{array}$ & $\begin{array}{l}\text { Effective wind } \\
\text { speed time (hour) }\end{array}$ & $\begin{array}{l}\text { Wind power density } \\
\left(\mathrm{W} / \mathrm{m}^{2}\right)\end{array}$ & $\begin{array}{l}\text { Turbulence } \\
\text { intensity }\end{array}$ \\
\hline Abundant region & 6.91 & $>5000$ & $>200$ & $<0.1$ \\
Less abundant region & $6.91-6.28$ & $4000-5000$ & $150-200$ & $0.1-0.2$ \\
Available region & $<6.28-4.36$ & $2000-4000$ & $<50-150$ & $0.2-0.3$ \\
Not abundant region & $<4.36$ & $<2000$ & $<50$ & $>0.3$ \\
\hline
\end{tabular}

\subsection{Environmental profits for wind project}

The environmental indexes for the evaluation of wind project sustainability can be summarized as: (1) two points which are the waste environment indicator such as $\mathrm{CO}_{2}$, $\mathrm{SO}_{2}$; (2) $\mathrm{NO}_{x}$ and unit per environmental profits [9].

1) $X_{9}$ refers to the amount of waste such as $\mathrm{CO}_{2}, \mathrm{SO}_{2}$, and $\mathrm{NO}_{x}$ in tons produced by the thermal plant divided by the energy produced in lifetime.

2) $X_{10}$ depends on the decrease of pollution from thermal power plants. The degree of pollution of thermal power is related to coal quality, boiler combustion and power generation technology. Taking the environmental profits of a wind project with a capacity of $100000 \mathrm{~kW}$ and an annual power generation of 2.3 billion $\mathrm{kWh}$ as an example, this project could save 87400 tons of standard coal, which is equal to 180000 tons raw coal. It could also reduce the emission of soot, ash residua, $\mathrm{SO}_{2}$, oxynitride and $\mathrm{CO}_{2}$ by 1150 tons, 27600 tons, 1403 tons, 1035 tons, 265000 tons, respectively. If $1 \mathrm{kWh}$ wind energy can avoid 0.18 RMB pollution cost, the environmental profit for 1000 MW wind energy would be 40 million RMB yearly.

\subsection{Economic benefits for wind project}

Economic factors can also influence the development of wind power projects [10]. The economic indexes that can be applied to evaluate sustainability are summarized below.

1) $X_{11}$ includes the maintenance cost, installation cost, capital cost, operation cost, replacement cost, and the interest rate over the project lifetime.

2) $X_{12}$ presents the value of the expected cash inflows of the wind project minus the costs of acquiring the project. This is one of the most commonly used financial techniques in performing an economic evaluation of a project.
3) $X_{13}$ is also one of the most important financial techniques, which is defined as (6), and $N_{\text {profit }}$ is net profit, $N_{\text {worth }}$ is net worth:

$X_{13}=\frac{N_{\text {profit }}}{N_{\text {worth }}}$

\subsection{Social benefits for wind project}

There is a wide positive range of social impacts from the production of wind electricity. For example, wind farms offer the job opportunity for electricity supply. The social benefits indexes that can be applied to evaluate sustainability of wind projects are summarized below [11].

1) $X_{14}$ refers to the increase in direct and indirect employment opportunities as a result of wind energy production and use in lifetime.

2) $X_{15}$ includes the paid hours per $\mathrm{kWh}$ produced in lifetime.

3) $X_{16}$ includes the total capital fund of wind power project per $\mathrm{kWh}$ produced in lifetime.

\section{Comprehensive weight calculation}

MCDM provides a comprehensive and reasonable evaluation of the wind power system based on multiple parameters that have a variety of attributes or have overall characteristics that are influenced by many factors [12]. As discussed, the core step of the MCDM analysis is appropriate calculation of weights for the selected indicators.

Firstly, the entropy weight (EW) method was applied to render an objective weighting value for each index. Secondly, AHP was employed to revise the objective weighting and fulfill a comprehensive weighting evaluation. The application of AHP can mitigate the interference caused by the objective factors in the assessment process. An index weight optimization method based on LCEA was then proposed to calculate the reasonable proportions of the weighting provided by AHP and EW, which then provides a comprehensive weighting value for each index. 


\subsection{Objective weight calculation based on EW}

Step 1: Calculate the probability of the indices for the preparation of the EW method.

Define a data matrix $\boldsymbol{X}$ :

$\boldsymbol{X}=\left[x_{i j}\right]_{n \times m}$

where $x_{i j}$ is the observed value of the $j^{\text {th }}$ alternative for the $i^{\text {th }}$ index, $x_{i j}>0$. The probability of $x_{i j}$ is defined as:

$\operatorname{Pr}\left(x_{i j}\right)=x_{i j} / \sum_{i=1}^{n} x_{i j}$

where $i=1,2, \ldots, n$ and $j=1,2, \ldots, m$.

Step 2: Calculate the entropy value.

Based on the first step, the entropy value of $x_{i j}$ is defined as:

$e_{i j}=-\frac{1}{\ln n} \sum_{i=1}^{n} \operatorname{Pr}\left(x_{i j}\right) \ln \operatorname{Pr}\left(x_{i j}\right)$

Step 3: Calculate discrimination factor.

The discrimination factor of $x_{i j}$ is defined as:

$g_{i j}=1-\mathrm{e}_{i j}$

Step 4: Calculate the objective weight based on EW method.

The objective weight matrix $\boldsymbol{q}_{\text {objective }}$ is defined as:

$\boldsymbol{q}_{\text {objective }}=\left[q_{i j}\right]_{n \times m}=\left[g_{i j} / \sum_{j=1}^{m} g_{i j}\right]_{n \times m}$

where $q_{i j}$ is the objective weight value of $q_{\text {objective }}$ matrix.

Note that the amount of information that can be provided by an index increases with decreasing entropy. Thus, the index has greater importance and a correspondingly greater objective weight.

\subsection{Calculation of subjective weights based on AHP}

Step 1: Structure a decision problem and articulate preferences over indices for the preparation of AHP.

AHP is based on three principles: first, the structure of a model is established; a comparative judgment of the alternatives and indices is then generated; and third, syntheses of the priorities are calculated. For the subjective weighting operation, the power grid experts selected options from the fundamental ranking criteria established according to [13], which is employed to simplify the representation of the degree of expert-chosen preferences to rank the indices.

Step 2: Construct an evaluation matrix.

Establish the comparison matrix $\boldsymbol{A}$ :

$\boldsymbol{A}=\left[a_{i j}\right]_{n \times n}$ where $a_{i j}$ represents the individual preference of the experts according to the relative importance of the two indices based on [13]. Here, $a_{i j}>0, a_{i i}=1$, and $a_{j i}=1 / a_{i j}$.

Step 3: Derive subjective weights.

This step aims to transform the pair-wise matrix $\boldsymbol{A}$ into a vector of subjective weights that can be attached to multiple outcomes. The vector of the subjective weights $p_{i j}$ belonging to $x_{i j}$ can be obtained from $\boldsymbol{A}$ by the eigenvector method.

$$
\left\{\begin{array}{l}
\boldsymbol{p}_{\text {subjective }}=\left[p_{i j}\right]_{n \times m} \\
\boldsymbol{A p}_{\text {subjective }}=\lambda_{\max } \boldsymbol{p}_{\text {subjective }}
\end{array}\right.
$$

where $\boldsymbol{p}_{\text {subjective }}$ is the eigenvector corresponding to the maximal eigenvalue $\lambda_{\max }$ of $\boldsymbol{A}$.

Step 4: Check the consistency.

The final consistency ratio $C_{R}$ is defined as:

$C_{R}=\frac{\lambda_{\max }-k}{\gamma(m-1)}$

The consistency is defined by the relation among the entries of $\boldsymbol{A}: a_{i j} a_{j k}=a_{i k}$; and $\gamma$ is the random consistency index. The values of $\gamma$ are based on [13] for different values of $k$. If $C_{R}<0.1, \boldsymbol{A}$ is deemed acceptable. Otherwise, $\boldsymbol{A}$ is considered inconsistent, and matrix $\boldsymbol{A}$ must be reviewed and improved until $C_{R}<0.1$.

\subsection{Comprehensive weight calculation based on LCEA}

Although a combination of subjective and objective evaluation methods can be expected to provide more accurate results, the relative importance that should be placed on the subjectively and objectively determined weights of the indices remains uncertain. As a result, the present study proposed the LCEA. As noted before, $p_{i j}$ and $q_{i j}$ are the subjective and objective weights values of $\boldsymbol{p}_{\text {subjective }}$ and $\boldsymbol{q}_{\text {objective }}$ matrixes, respectively, thereby defining the comprehensive weight as:

$\boldsymbol{\omega}_{\text {com }}=\left[\omega_{i j}\right]_{n \times m}=\left[k_{i}^{(1)} p_{i j}+k_{i}^{(2)} q_{i j}\right]_{n \times m}$

where $\omega_{i j}$ is the value of comprehensive weight matrix, $k_{i}^{(1)}$ and $k_{i}^{(2)}$ are constants that satisfy the conditions $k_{i}^{(1)}>0, k_{i}^{(2)}>0$, and $\left(k_{i}^{(1)}\right)^{2}+\left(k_{i}^{(2)}\right)^{2}=1$. The comprehensive values $y_{i}$ in (16) are defined by applying additive method:

$y_{i}=\sum_{j=1}^{m} \omega_{i j} x_{i j}=\sum_{j=1}^{m}\left(k_{i}^{(1)} p_{i j}+k_{i}^{(2)} q_{i j}\right) x_{i j}$

The wind project will become more advantageous with increasing values of $y_{i}$. Meanwhile, the weights of indexes actually belong to random variable, which can be described 
as the sum of the mean value and the random error. The deviation $\varepsilon_{i}$ of $y_{i}$ based on minimum deviation is defined as:

$\varepsilon_{i}=\sum_{j=1}^{m}\left[\left(\omega_{i j}-\omega_{i j}^{j}\right) x_{i j}\right]^{2}$

Here, when the sum of the comprehensive values, $\sum_{i=1}^{n} y_{i}$, is at its maximum while the sum of the deviation values, $\sum_{i=1}^{n} \varepsilon_{i}$ is at its minimum, then $k_{i}^{(1)}$ and $k_{i}^{(2)}$ can be determined. Combined (16) and (17):

$$
\left\{\begin{array}{l}
\max \sum_{i=1}^{n} y_{i}=\max \sum_{i=1}^{n} \sum_{j=1}^{m} \omega_{i j} x_{i j} \\
\min \sum_{i=1}^{n} \varepsilon_{i}=\min \left[\sum_{i=1}^{n} \sum_{j=1}^{m}\left(\omega_{i j}-\omega_{i j}^{j}\right) x_{i j}\right]^{2} \\
1 \geq \omega_{i j} \geq 0 \quad j=1,2, \cdots, m
\end{array}\right.
$$

Then transfer the multi-objective optimization problem into single objective optimization problem by (19):

$$
\left\{\begin{array}{c}
\min \lambda \sum_{i=1}^{n} \sum_{j=1}^{m}\left[\left(\omega_{i j}-\omega_{i j}^{j}\right) x_{i j}\right]^{2}+ \\
(1-\lambda) \max \sum_{i=1}^{n} \sum_{j=1}^{m} \omega_{i j} x_{i j} \\
1 \geq \omega_{i j} \geq 0 \quad j=1,2, \cdots, m
\end{array}\right.
$$

where $\lambda$ is the balance coefficient. The function of $\lambda$ is to balance the sum of the comprehensive values $y_{i}$ and deviation values $\varepsilon_{i}$. These two parts are making identical contribution to (19). Thus, the value of $\lambda$ is usually defined as 0.5 [14]. According to the above stated conditions for $k_{i}^{(1)}$ and $k_{i}^{(2)}$, the LCEA is defined as:

$$
\begin{aligned}
L\left(k_{i}^{(1)}, k_{i}^{(2)}, \mu\right)= & \lambda \sum_{i=1}^{n} \sum_{j=1}^{m}\left\{\left[\left(k_{i}^{(1)} p_{i j}+k_{i}^{(2)} q_{i j}\right)\right.\right. \\
& \left.\left.-\left(k_{i}^{(1)} p_{i j}^{j}+k_{i}^{(2)} q_{i j}^{j}\right)\right] x_{i j}\right\}^{2} \\
& +(1-\lambda) \sum_{i=1}^{n} \sum_{j=1}^{m}\left(k_{i}^{(1)} p_{i j}+k_{i}^{(2)} q_{i j}\right) x_{i j} \\
& -\mu\left(\left(k_{i}^{(1)}\right)^{2}+\left(k_{i}^{(2)}\right)^{2}-1\right)
\end{aligned}
$$

where $\mu$ is the undetermined coefficient of constraints which can be calculated by partial derivatives of the LCEA, when $\mu$ is set to zero. Then, the partial derivatives of the LCEA with respect to $k_{i}^{(1)}, k_{i}^{(2)}$, and $\mu$ are set to zero, as in (21).

$$
\left\{\begin{aligned}
\frac{\partial L}{\partial k_{i}^{(1)}} & =2 \lambda \sum_{i=1}^{n} \sum_{j=1}^{m}\left\{\left[\left(k_{i}^{(1)} p_{i j}+k_{i}^{(2)} q_{i j}\right)\right.\right. \\
& \left.\left.\left(k_{i}^{(1)} p_{i j}^{j}+k_{i}^{(2)} q_{i j}^{j}\right)\right] x_{i j}\right\} \\
& \times\left(p_{i j}-p_{i j}^{j}\right) x_{i j} \\
& +(1-\lambda) \sum_{i=1}^{n} \sum_{j=1}^{m} p_{i j} x_{i j}-2 \mu k_{i}^{(1)}=0 \\
\frac{\partial L}{\partial k_{i}^{(2)}} & =2 \lambda \sum_{i=1}^{n} \sum_{j=1}^{m}\left\{\left[\left(k_{i}^{(1)} p_{i j}+k_{i}^{(2)} q_{i j}\right)\right.\right. \\
& \left.\left.-\left(k_{i}^{(1)} p_{i j}^{i}+k_{i}^{(2)} q_{i j}^{j}\right)\right] x_{i j}\right\} \\
& \times\left(q_{i j}-q_{i j}^{j}\right) x_{i j} \\
& +(1-\lambda) \sum_{i=1}^{n} \sum_{j=1}^{m} q_{i j} x_{i j}-2 \mu k_{i}^{(2)}=0 \\
\frac{\partial L}{\partial \mu}= & -\left(\left(k_{i}^{(1)}\right)^{2}+\left(k_{i}^{(2)}\right)^{2}\right)=0 \\
k_{i}^{(1)}>0 & \\
k_{i}^{(2)}>0 & \\
\left(k_{i}^{(1)}\right)^{2}+ & \left(k_{i}^{(2)}\right)^{2}=1
\end{aligned}\right.
$$

Equation (21) consists of $3 n+1$ sub-equations with a total number of $3 n+1$ variables which can be solved by MATLAB, then we can obtain the values of $k_{i}^{(1)}$ and $k_{i}^{(2)}$. Substitute $k_{i}^{(1)}$ and $k_{i}^{(2)}$ into (15), then we can obtain comprehensive weights $\omega_{\text {com }}$.

\subsection{Comprehensive evaluation of fuzzy TOPSIS algorithm}

Once the index weights are calculated, the wind project assessment can be used to compare wind projects and identify the most sustainable wind project with the help of fuzzy TOPSIS. The fuzzy set theory solves the problems like uncertain and imprecise evaluation data, thereby upgrading the conventional TOPSIS method. The fuzzy TOPSIS algorithm is proposed by combining the fuzzy set theory and the TOPSIS method to evaluate alternatives by calculating the geometric distances from the benefit and cost ideal solutions. The specific steps of fuzzy TOPSIS are presented as follows:

Step 1: Normalize the initial index system.

Generally, the attributes of the different indexes may be different. Some indexes hold benefit-type contributions, namely the larger the better, such as in installed capacity and annual electricity production. On the contrary, some indexes are costly and require smaller values, such as for unplanned outage hours and turbulence intensity. 
Moreover, the unit of $X_{1}$ is $\mathrm{kW}$ while the unit of $X_{2}$ is $\mathrm{kWh}$. And the magnitude order of $X_{1}$ and $X_{2}$ also differs. It is thus not fair to compare different kinds of magnitude order of indexes, because those with the largest values would determine the final results. Therefore, the vector norm method was employed to make the indexes dimensionless and to assign each index a comprehensive weight, ultimately allowing them to determine the final results. The dimensionless value of $x_{i j}$ is defined as:

$x_{i j}^{*}=\left\{\begin{array}{l}x_{i j} / \sqrt{\sum_{i=1}^{n} x_{i j}^{2}} \\ \sqrt{\sum_{i=1}^{n} x_{i j}^{2}} / x_{i j}\end{array}\right.$

where $i=1,2, \ldots, n ; j=1,2, \ldots, m ; x_{i j} \geq 0, x_{i j} \in(0,1)$; and $\sum_{i=1}^{n}\left(x_{i j}^{*}\right)^{2}=1$. For the benefit-type index, $x_{i j}^{*}=$ $x_{i j} / \sqrt{\sum_{i=1}^{n} x_{i j}^{2}}$ was employed to normalize the initial index, whereas $x_{i j}^{*}=\sqrt{\sum_{i=1}^{n} x_{i j}^{2}} / x_{i j}$ was employed to normalize the cost-type index.

Step 2: Aggregate the fuzzy sets for indexes of all alternatives.

The major advantage of fuzzy logic systems is human terms and rules. In order to capture the uncertainty inherent to linguistic terms, fuzzy membership functions (MFs) are used. The fuzzy set of the fuzzy MF has a high resolution and controls for sensitivity when the MF shape is pointed. We thus chose a triangular fuzzy number (TFN) due to its simple computation process, a wide range for recording indexes and high sensitivity. TFN is defined according to the triplet $V=\left\{V^{L}, V^{M}, V^{H}\right\}$. The membership function $r_{i j}\left(\tilde{x}_{i j}\right)$ of a TFN is expressed as:

$r_{i j}\left(\tilde{x}_{i j}\right)= \begin{cases}0 & \tilde{x}_{i j}<V^{L} \\ \frac{\tilde{x}_{i j}-V^{L}}{V^{M}-V^{L}} & V^{L} \leq \tilde{x}_{i j}<V^{M} \\ \frac{V^{H}-\tilde{x}_{i j}}{V^{H}-V^{M}} & V^{M} \leq \tilde{x}_{i j}<V^{H} \\ 0 & \tilde{x}_{i j}>V^{H}\end{cases}$

where $V^{L}, V^{M}$, and $V^{H}$ are precise numbers, where $V^{L}<V^{M}<V^{H}$, and $V^{L}$ and $V^{H}$ are the available bounds for the evaluation of the criteria uncertainty. The criteria performance is determined with the linguistic terms obtained from the decision makers. The fuzzy decision matrix $\boldsymbol{R}$ for $r_{i j}=\left\{r_{i j}^{L}, r_{i j}^{M}, r_{i j}^{H}\right\}$ is defined as follows, where $r_{i j}^{L}, r_{i j}^{M}$, and $r_{i j}^{H}$ are the values of matrix $\boldsymbol{R}$, and $r_{i j}^{L}<r_{i j}^{M}<r_{i j}^{H}$.
$\boldsymbol{R}=\left[r_{i j}\right]_{n \times n}$

Step 3: Structure the weighted normalized fuzzy decision matrix.

Considering the importance differences among the evaluation indexes, the normalized weighted fuzzy decision matrix $\boldsymbol{Y}$ was constructed by multiplying the fuzzy decision matrix $\boldsymbol{R}$ with the weights of criteria as:

$\boldsymbol{Y}=\boldsymbol{R} \boldsymbol{\omega}_{\text {com }}=\left[y_{i j}\right]_{n \times m}$

Step 4: Determine the two types of ideal solutions.

All criteria must be divided into two kinds, specifically the benefit ideal solution $Y^{+}$and the cost ideal solution $Y^{-}$, which can be computed by (26) and (27), respectively, where $J$ is a benefit criterion while $\boldsymbol{J}^{\prime}$ is a cost criterion.

$$
\begin{aligned}
Y^{+}= & \left\{\left(y_{i j}^{\max } \mid j \in J\right),\left(y_{i j}^{\min } \mid j \in J^{\prime}\right), i=1,2, \cdots, m\right\} \\
& =\left\{y_{1}^{+}, y_{2}^{+}, \cdots, y_{j}^{+}, \cdots, y_{n}^{+}\right\} \\
Y^{-}= & \left\{\left(y_{i j}^{\min } \mid j \in J\right),\left(y_{i j}^{\max } \mid j \in J^{\prime}\right), i=1,2, \cdots, m\right\} \\
& =\left\{y_{1}^{-}, y_{2}^{-}, \cdots, y_{j}^{-}, \cdots, y_{n}^{-}\right\}
\end{aligned}
$$

Step 5: Calculate the distances of each alternative from the two types of ideal solutions.

The geometric distance is the common method to calculate the distance between two triangular values. Recently, the Euclid distance has demonstrated its own advantages in terms of discrimination and evaluation. Therefore, the distance $D_{i}^{+}$and $D_{i}^{-}$of each alternative form $Y^{+}$and $Y^{-}$can be obtained based on (28) and (29):

$D_{i}^{+}=\sqrt{\sum_{j=1}^{n}\left(y_{j}^{+}-y_{i j}\right)^{2}}$

$D_{i}^{-}=\sqrt{\sum_{j=1}^{n}\left(y_{j}^{-}-y_{i j}\right)^{2}}$

Step 6: Calculate the closeness coefficients of all alternatives.

The closeness coefficient $C_{i}$ can be employed to reflect the distance closest to $D_{i}^{+}$as well as $D_{i}^{-}$, which can be computed by:

$C_{i}=\frac{D_{i}^{+}}{D_{i}^{-}+D_{i}^{+}}$

where $0 \leq C_{i} \leq 1$ and higher values of $C_{i}$ result in a better design performance. The values of $C_{i}$ can be ranked to obtain the final results. 


\section{Experimental applications and analysis}

\subsection{Experimental setup}

The proposed method is designed and tested in line with the actual operation of a power grid in Hami City, China. Hami, which is a mainland city, not only has an abundance of wind energy resources but also exhibits multi-level voltage and high penetration of wind power, thereby rendering it ideal for demonstrating the proposed method. To promote the sustainable development and management of the wind power projects and make the utmost use of the wind resource, the sustainability of different regional wind projects of the Hami grid must be assessed and ranked. The tested power system structure exhibits a total wind capacity of $4885.2 \mathrm{MW}$, and uses $220 \mathrm{kV}$ lines to connect to $750 \mathrm{kV}$ transformer substations.

The Hami grid is divided into three main regions according to the geographical location of wind power groups, i.e., regions A, B, and C. The wind groups of three regions are thereby named as wind project $\mathrm{A}, \mathrm{B}$, and $\mathrm{C}$ for simplicity. The main parameters, according to the evaluation index system obtained from the Hami Statistics Bureau and verified by wind experts, are shown in Table 2 . According to Table 2, wind project A exhibits the largest installation capacity, annual electricity production, and the highest environmental profits, whereas wind project B exhibits the most favorable wind recourses, which can be obtained according to Table 1, despite being the smallest installation. However, all the parameters of wind project $\mathrm{C}$ appears to be average.

Table 2 Parameters of test system

\begin{tabular}{llll}
\hline Index & $\mathrm{A}$ & $\mathrm{B}$ & $\mathrm{C}$ \\
\hline$X_{1}(\mathrm{~kW})$ & 2641.1 & 440.9 & 1803.2 \\
$X_{2}(\mathrm{kWh})$ & 127235.2 & 74511.6 & 176430.4 \\
$X_{3}$ (hour) & 6230 & 6486 & 5763 \\
$X_{4}($ hour $)$ & 197 & 172 & 185 \\
$X_{5}(\mathrm{~m} / \mathrm{s})$ & 5.2 & 6.1 & 4.7 \\
$X_{6}($ hour $)$ & 6250 & 7556 & 4021 \\
$X_{7}\left(\mathrm{~kW} / \mathrm{m}^{2}\right)$ & 918.54 & 923.6 & 873.22 \\
$X_{8}$ & 0.1 & 0.07 & 0.09 \\
$X_{9}($ ton $/ \mathrm{kWh})$ & 24000 & 19000 & 35000 \\
$X_{10}(\mathrm{RMB} / \mathrm{kW})$ & 98.4 & 17.6 & 72.1 \\
$X_{11}(\mathrm{RMB} / \mathrm{kWh})$ & 0.25 & 0.21 & 0.23 \\
$X_{12}(\%)$ & 0.77 & 0.71 & 0.69 \\
$X_{13}(\%)$ & 0.98 & 0.93 & 0.91 \\
$X_{14}(\mathrm{No} . / \mathrm{kWh})$ & 59 & 34 & 41 \\
$X_{15}(\%)$ & 0.22 & 0.18 & 0.2 \\
$X_{16}(\mathrm{RMB} / \mathrm{kWh})$ & 110 & 70 & 160 \\
\hline
\end{tabular}

\subsection{Data preprocessing and calculation}

The above indexes of wind projects $\mathrm{A}, \mathrm{B}$, and $\mathrm{C}$ are reprocessed based on (22). We can obtain the standardization matrix $\boldsymbol{X}$, as presented in (31). Equation (31) demonstrates the differences of some indexes' values, such as in $X_{1}, X_{2}, X_{10}$, and $X_{14}$ of the three wind projects. On the contrary, other indexes' values, such as $X_{3}, X_{4}, X_{7}, X_{13}$, and $X_{15}$, are similar. The sustainability of each region cannot be defined by a single index only. That is to say, the sustainability of a wind power system cannot be accurately determined using only parts of its indexes. Therefore, a comprehensive evaluation of the sustainability of the wind power project must be performed using a comprehensive index system, as is the case here:

$\boldsymbol{X}=\left[\begin{array}{lll}0.8181 & 0.1366 & 0.5586 \\ 0.5534 & 0.3241 & 0.7673 \\ 0.5833 & 0.6072 & 0.5395 \\ 0.5387 & 0.6170 & 0.5737 \\ 0.5596 & 0.6565 & 0.5058 \\ 0.5897 & 0.7129 & 0.3794 \\ 0.5857 & 0.5890 & 0.5568 \\ 0.4836 & 0.6909 & 0.5374 \\ 0.5711 & 0.7214 & 0.3916 \\ 0.7984 & 0.1428 & 0.5850 \\ 0.5168 & 0.6460 & 0.5618 \\ 0.6139 & 0.5661 & 0.5501 \\ 0.6016 & 0.5709 & 0.5587 \\ 0.7423 & 0.4277 & 0.5158 \\ 0.6330 & 0.5179 & 0.5754 \\ 0.5535 & 0.3522 & 0.7547\end{array}\right]$

\subsection{Calculation of comprehensive weight based on AHP-EW}

The objective of the weight indexes can be calculated by the EW method, specifically by (8)-(11), as shown in (32).

$\boldsymbol{q}_{\text {objective }}=\left[\begin{array}{lll}0.075332 & 0.025102 & 0.062952 \\ 0.058995 & 0.047023 & 0.076564 \\ 0.061041 & 0.071037 & 0.061567 \\ 0.057970 & 0.071741 & 0.064029 \\ 0.059428 & 0.074507 & 0.059048 \\ 0.061476 & 0.078281 & 0.048730 \\ 0.061208 & 0.069706 & 0.062826 \\ 0.053982 & 0.076833 & 0.061408 \\ 0.060217 & 0.078830 & 0.049795 \\ 0.074238 & 0.025961 & 0.064829 \\ 0.056411 & 0.073784 & 0.063180 \\ 0.063081 & 0.068003 & 0.062341 \\ 0.062270 & 0.068367 & 0.062957 \\ 0.071031 & 0.056752 & 0.059804 \\ 0.064320 & 0.064277 & 0.064155 \\ 0.059002 & 0.049794 & 0.075816\end{array}\right]$


The EW method emphasizes the difference between the indexes. Therefore, the present study also applies the AHP method as directed by the experts to revise the calculated results of the objective weights calculation and generate comprehensive evaluation results.

For subjective weighting, experts are invited to provide scores on the basis of the pairwise comparison of indices to represent the relative importance of the various indicators. Here, it is assumed that the subjective weighting of each index is equivalent in all wind farms. The comparison matrix and the weight of each index are obtained using (12)-(14). The first pairwise comparison matrix from the sub-target of view $(\boldsymbol{A P})$ is:

$$
\boldsymbol{A P}=\left[\begin{array}{ccccc}
1 & 5 & 3 & 1 / 2 & 1 / 2 \\
1 / 5 & 1 & 1 / 2 & 1 / 3 & 1 / 3 \\
1 / 3 & 2 & 1 & 1 / 3 & 1 / 3 \\
2 & 3 & 3 & 1 & 1 / 2 \\
2 & 3 & 3 & 2 & 1
\end{array}\right]
$$

The second pairwise comparison matrix from wind technological competitiveness of view $\left(\boldsymbol{P}_{1} \boldsymbol{X}\right)$ is:

$$
\boldsymbol{P}_{1} \boldsymbol{X}=\left[\begin{array}{cccc}
1 & 1 / 2 & 1 / 3 & 1 / 5 \\
2 & 1 & 1 / 2 & 1 / 3 \\
3 & 2 & 1 & 1 / 2 \\
5 & 3 & 2 & 1
\end{array}\right]
$$

Likewise, the second third, fourth, and fifth pair-wise comparison matrix from the rest of wind perspectives of view $\left(\boldsymbol{P}_{2} \boldsymbol{X}, \boldsymbol{P}_{3} \boldsymbol{X}, \boldsymbol{P}_{4} \boldsymbol{X}\right.$, and $\left.\boldsymbol{P}_{5} \boldsymbol{X}\right)$ are defined as follows:

$\boldsymbol{P}_{2} \boldsymbol{X}=\left[\begin{array}{cccc}1 & 1 / 3 & 1 / 3 & 1 / 2 \\ 3 & 1 & 1 / 2 & 1 / 2 \\ 3 & 2 & 1 & 1 / 2 \\ 2 & 2 & 2 & 1\end{array}\right]$

$\boldsymbol{P}_{3} \boldsymbol{X}=\left[\begin{array}{cc}1 & 1 / 3 \\ 3 & 1\end{array}\right]$

$\boldsymbol{P}_{4} \boldsymbol{X}=\left[\begin{array}{ccc}1 & 1 / 3 & 1 / 3 \\ 3 & 1 & 1 / 2 \\ 3 & 2 & 1\end{array}\right]$

$\boldsymbol{P}_{5} \boldsymbol{X}=\left[\begin{array}{ccc}1 & 1 / 2 & 1 / 2 \\ 2 & 1 & 1 / 2 \\ 2 & 2 & 1\end{array}\right]$

The final subjective weights is $\boldsymbol{p}_{\text {subjective }}=[0.0188$, $0.0334,0.0579,0.1029,0.0073,0.0137,0.0192,0.0250$,

Table 3 Calculation results of TOPSIS

\begin{tabular}{llll}
\hline TOPSIS & $\mathrm{A}$ & $\mathrm{B}$ & $\mathrm{C}$ \\
\hline$Y^{+}$ & 0.326160 & 0.235290 & 0.446200 \\
$Y^{-}$ & 0.036400 & 0.009250 & 0.026380 \\
$D^{+}$ & 0.859770 & 0.583420 & 1.350070 \\
$D^{-}$ & 0.503060 & 0.482740 & 0.575913 \\
\hline
\end{tabular}

$0.0237,0.0710,0.0352,0.0839,0.1331,0.0733,0.1164$, $0.1848]^{\mathrm{T}}$. Moreover, the proportions of the objective and subjective weights can be calculated by (17)-(21), and the comprehensive weight index matrixes $\omega_{\text {com }}$ are defined by (16) and are calculated in (39).

$$
\omega_{\text {com }}=\left[\begin{array}{lll}
0.0981554 & 0.0677479 & 0.0890087 \\
0.1266258 & 0.1215110 & 0.1357045 \\
0.2034724 & 0.2066914 & 0.2036309 \\
0.3494975 & 0.3520437 & 0.3505535 \\
0.0650530 & 0.0790667 & 0.0647055 \\
0.0790040 & 0.0926842 & 0.0695484 \\
0.0927223 & 0.0985392 & 0.0937984 \\
0.1055014 & 0.1188267 & 0.1094872 \\
0.0839086 & 0.0981260 & 0.0767726 \\
0.1903898 & 0.1772315 & 0.1869218 \\
0.1213987 & 0.1303826 & 0.1246885 \\
0.2636508 & 0.2648715 & 0.2634748 \\
0.4111523 & 0.4121199 & 0.4112570 \\
0.2432779 & 0.2394985 & 0.2402400 \\
0.3749326 & 0.3749252 & 0.3749044 \\
0.5892963 & 0.5884457 & 0.5912164
\end{array}\right]
$$

\subsection{Calculation of final results by fuzzy TOPSIS}

The fuzzy TOPSIS method is employed to calculate the final comprehensive evaluation results considering the system functionality and proportionality, thereby disposing the information loss caused by the comprehensive weights. After reviewing the general information of the three wind projects, experts provides the present study with linguistic ratings for the performance of the 16 sub-indexes. The nondimensionalized fuzzy decision matrix $\boldsymbol{Y}$ is constructed, as shown in (40) using (22)-(24). Further, the positive ideal solution $Y^{+}$and the negative ideal solution $Y^{-}$are determined from the weighted normalized decision matrix using (26), (27). Following this, the Euclidean distances $\left(D^{+}\right.$and $D^{-}$) between each alternative from $\mathrm{Y}^{+}$and $Y^{-}$are calculated using (28), (29). In the next step, the closeness coefficient $C_{i}$ of the alternatives is calculated using (30). The results for $Y^{+}, Y^{-}, D^{+}$and $D^{-}$are summarized in Table 3. Finally, the closeness coefficient $C_{i}$ is presented in Table 4 . The alternatives are arranged in descending order as $\mathrm{C}>\mathrm{A}>\mathrm{B}$. The following conclusions are generated according to the obtained values of $C_{i}$ in Table 4. Firstly, the wind project $\mathrm{C}$ is the most sustainable aspect of the established power grid. Secondly, and conversely, the

Table 4 Final ranks of three wind projects by fuzzy TOPSIS

\begin{tabular}{lll}
\hline Wind project & CE index & Rank \\
\hline A & 0.630872210 & 2 \\
B & 0.547217201 & 3 \\
C & 0.700978119 & 1 \\
\hline
\end{tabular}


minimal value of wind project B characterizes the latter as the least sustainable wind project.

$\boldsymbol{Y}=\left[\begin{array}{ccc}0.080304 & 0.009253 & 0.049718 \\ 0.07007 & 0.039377 & 0.104128 \\ 0.118676 & 0.125507 & 0.109866 \\ 0.188279 & 0.217216 & 0.201097 \\ 0.036405 & 0.051906 & 0.032729 \\ 0.04659 & 0.066079 & 0.026387 \\ 0.05431 & 0.058035 & 0.05223 \\ 0.051024 & 0.082097 & 0.058835 \\ 0.047922 & 0.07079 & 0.030066 \\ 0.152002 & 0.025308 & 0.109347 \\ 0.06274 & 0.084229 & 0.070044 \\ 0.161861 & 0.149939 & 0.144947 \\ 0.247359 & 0.235291 & 0.229749 \\ 0.180578 & 0.102445 & 0.123919 \\ 0.237324 & 0.194171 & 0.215733 \\ 0.326158 & 0.207255 & 0.44621\end{array}\right]$

The case study suggests that the proposed model can provide a new and feasible way for seeking the most sustainable wind project from a list of available options. To validate the plausibility of the final results, the ranking procedure is repeated with the ordered weighted averaging (OWA), the results of which are shown in Table 5. As a weighted average method, the OWA operator is used widely in various application studies. OWA is considered as a convenient modeling approach and is readily understood in terms of the measures it generates. The comparisons of the results reveal identical fuzzy TOPSIS and OWA ranking results, thereby implying the dependability of the approach.

According to Table 5, wind project $\mathrm{C}$ remains in the first place, followed by wind project $\mathrm{A}$, and wind project $\mathrm{B}$ as the least preferred option. In general, the range of values for the fuzzy TOPSIS method provides a larger difference between wind projects $\mathrm{A}, \mathrm{B}$, and $\mathrm{C}$, thereby suggesting the applicability of the fuzzy TOPSIS method in addressing the greater discrimination between the alternatives. The ranking index formed by the fuzzy TOPSIS method considers both the benefit of the ideal solution and cost ideal solution of each index, thereby enabling researchers to approach the selection problem of the sustainable level of the wind projects from multiple perspectives rather than simply selecting the highest OWA score. Therefore, the fuzzy TOPSIS method incorporates the concept of contradiction

Table 5 Final ranks of three wind projects by OWA

\begin{tabular}{lll}
\hline Wind project & OWA & Rank \\
\hline A & 0.633242233 & 2 \\
B & 0.611914944 & 3 \\
C & 0.665330432 & 1 \\
\hline
\end{tabular}

into the ranking of the compromise solutions, which can improve the quality of ranking results.

\section{Sensitivity analysis}

In Section 3, the values of the weights were determined according to the proposed comprehensive weight calculation method. However, the weight values could be changed following the application of other kinds of methods. Thus, we conducted a sensitivity analysis on these weight values. According to Fig. 1, the 16 sub-criteria were divided into 5 analysis levels, namely technology, wind resource, environment, economy, and society groups. All the initial subcriteria of each levels were assumed to exhibit rate changes of $0.3,0.2,0.1,-0.1,-0.2$, and -0.3 , respectively, and all the base weights are shown in (39). The sustainable level values and ranks of the wind projects were then recalculated as shown in Fig. 2. $X$-axis represents the rate of base weights of $X_{i}$ index, and $Y$-axis is the current values of weights of wind projects $\mathrm{A}, \mathrm{B}$, and $\mathrm{C}$.

According to Fig. 2, the final score of the three alternatives, specifically wind projects $\mathrm{A}, \mathrm{B}$, and $\mathrm{C}$, exhibited a sharp decrease when the weight of sub-criteria $X_{3}$ became less important. Thus, they are most sensitive to the weight of $X_{3}$. However, wind project $\mathrm{C}$ maintained its first ranking as the base case throughout $X_{3}$ weight changes. The weight decreases in $X_{1}, X_{2}$, and $X_{4}$ generated a more or less decline in the scores of wind projects $\mathrm{A}, \mathrm{B}$, and $\mathrm{C}$. However, the weight changes in the technology group did not affect wind project $\mathrm{C}$ as it maintained its highest scores in the sustainable evaluation of the wind projects.

The sensitivity analysis results of the $X_{5}, X_{6}, X_{7}$, and $X_{8}$ weights are shown in Fig. 3 . The sub-criteria weight changes in the wind resource group resulted in small score variations in wind projects $\mathrm{A}, \mathrm{B}$, and $\mathrm{C}$ following $X_{5}, X_{6}$,

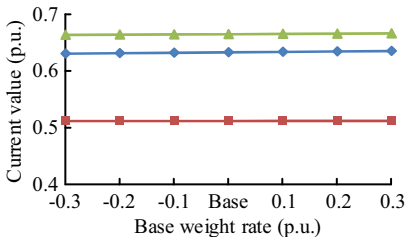

(a) $X_{1}$

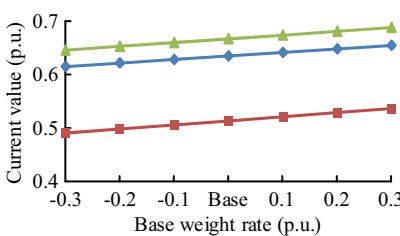

(c) $X_{3}$

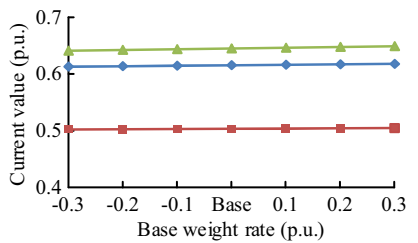

(b) $X_{2}$

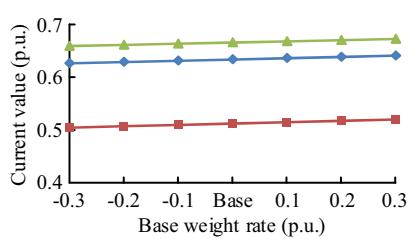

(d) $X_{4}$ $\rightarrow$ Wind project $\mathrm{A} ;-$ Wind project $\mathrm{B} ; \leadsto$ Wind project $\mathrm{C}$

Fig. 2 Sub-criteria sensitivity analysis results of technology groups 

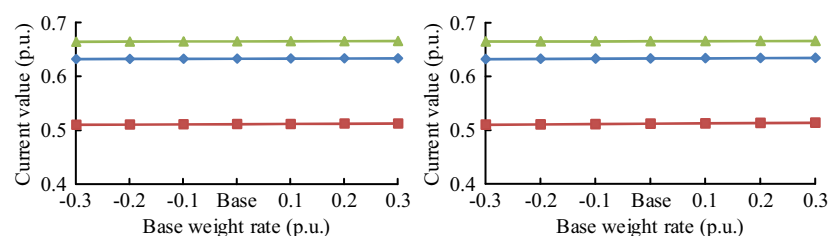

(a) $X_{5}$

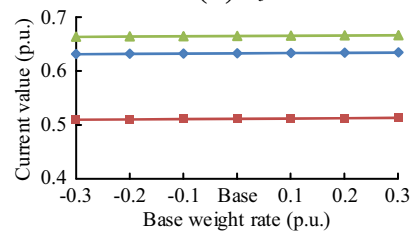

(c) $X_{7}$

(b) $X_{6}$

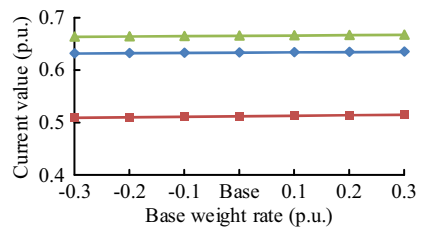

(d) $X_{8}$

$\rightarrow$ Wind project $\mathrm{A} ; \rightarrow$ Wind project $\mathrm{B} ;-$ Wind project $\mathrm{C}$

Fig. 3 Sub-criteria sensitivity analysis results in wind resource group

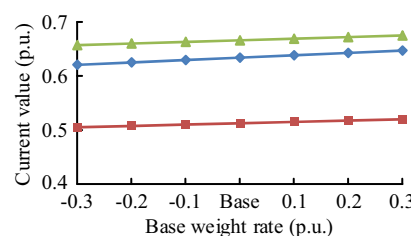

(a) $X_{9}$

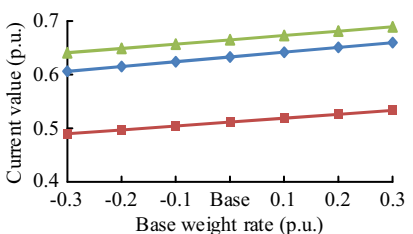

(b) $X_{10}$ $\rightarrow$ Wind project $\mathrm{A} ;-$ Wind project $\mathrm{B} ;-$ Wind project $\mathrm{C}$

Fig. 4 Sub-criteria sensitivity analysis results in environment group

$X_{7}$, and $X_{8}$ sub-criteria changes. Likewise, wind projects $\mathrm{C}$ and $\mathrm{B}$ were deemed the optimal and worst regional wind projects, respectively, for all sub-criteria weight changes in the wind resource group.

For the sub-criteria in the environment group, the three alternatives were more sensitive to the weight of sub-index $X_{10}$ than to sub-index $X_{9}$, as shown in Fig. 4. The score of wind project $\mathrm{C}$ in all three projects was maintained the highest.

The sensitivity analysis results of the weights of $X_{11}$, $X_{12}$, and $X_{13}$ are shown in Fig. 5. According to Fig. 5, the final score of the three alternatives exhibited a slight decrease following a decrease in the weight of sub-criteria of economy group. The weight of $X_{13}$ exhibited the most sensitivity. However, wind project $C$ maintained the highest scores in the economy group for all economy group weights changes.

Figure 6 indicates that the scores of all three alternatives exhibited a small variation trend in the case of the weight fluctuations of $X_{15}$ and $X_{16}$. However, the scores of the three wind projects maintained the same decreasing trend as the weight of $X_{14}$ became less important. Moreover, just as that in the other four sub-indexes groups, wind projects $\mathrm{C}$ and $\mathrm{B}$ were still deemed the best and worst wind projects, respectively, for all society group sub-criteria weight change.

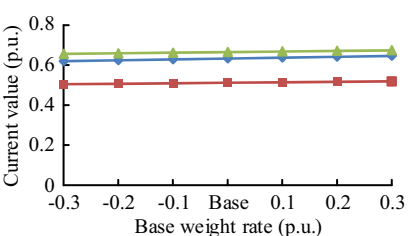

(a) $X_{11}$

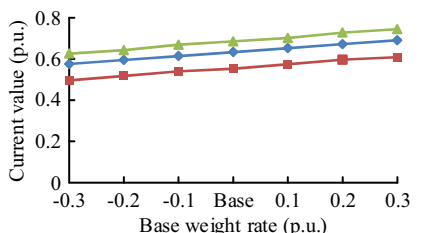

(c) $X_{13}$

$\rightarrow$ Wind project $\mathrm{A} ;-$ Wind $\operatorname{project} \mathrm{B} ;-$ Wind $\operatorname{project} \mathrm{C}$

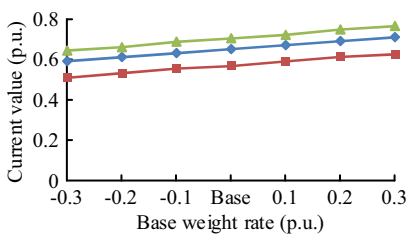

(a) $X_{14}$

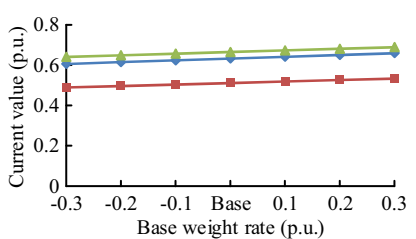

(b) $X_{12}$

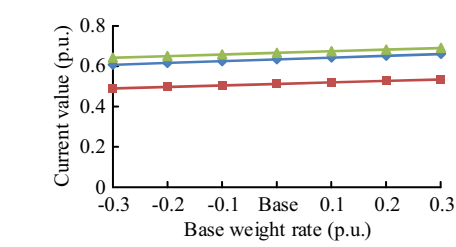

(c) $X_{16}$

$\rightarrow$ Wind project $\mathrm{A} ;-$ Wind project $\mathrm{B} ;-$ Wind project $\mathrm{C}$

Fig. 6 Sub-criteria sensitivity analysis results in society group

Above all, three wind projects always keep their ranks, no matter how the sub-criteria weights change. It can be verified that the performance evaluation of wind projects using the proposed comprehensive weights calculation method and fuzzy TOPSIS is robust.

\section{Conclusion}

The present study proposes a combined MCDM framework for the sustainable level of the selection model of wind projects. A hierarchical wind project evaluation criteria framework is proposed and validated. Two MCDM weights decision methods, specifically EW and AHP, are combined by the LCEA method to calculate this set of multilevel criteria, which consists of five main dimensions and 16 sub-criteria. An empirical case study containing three Hami City wind projects in China is used to exemplify the approach and rank the sustainable level of each 
wind project by the fuzzy TOPSIS method. The results of the case study are robust with regards to the OWA method. In addition, a sensitive analysis is also applied to verify the robustness and effectiveness of the proposed weight calculation approach. The model can thus not only be compatible with different index systems but also identify the greater or weaker level of sustainability for a wind project.

The present study aims to guide researchers and other investors to easily forecast the sustainable performance of wind projects and decide accordingly. This study presents its originality in its comprehensive criteria structure, which is balanced on the five dimensions of sustainability of the wind project. In addition, the combination of its proposed comprehensive weights calculation method (AHP and EW, optimized by LCEA) with the fuzzy TPOSIS method in the selection problem of the sustainable level of the wind project has not been previously published in literature. Distinguishing wind projects from general wind technologies can reduce the over-simplification of decision problems and aid in the evaluation of alternatives in the light of more specific data. The next stage of this research will focus on the design of an application software based on the proposed method to quickly calculate and analyze the sustainability level of wind projects.

Acknowledgements This work was supported by National Natural Science Foundation of China (No. 51667020), University research projects of Xinjiang Province (No. XJEDU2017I002), Xinjiang Province Key Laboratory Project (No. XJDX1402) and Doctoral Innovation Project (No. XJUBSCX-2015015).

Open Access This article is distributed under the terms of the Creative Commons Attribution 4.0 International License (http:// creativecommons.org/licenses/by/4.0/), which permits unrestricted use, distribution, and reproduction in any medium, provided you give appropriate credit to the original author(s) and the source, provide a link to the Creative Commons license, and indicate if changes were made.

\section{References}

[1] Tan ZF, Ngan HW, Wu Y et al (2013) Potential and policy issues for sustainable development of wind power in China. J Mod Power Syst Clean Energy 1(3):204-215

[2] Yuan J, Sun S, Shen J (2014) Wind power supply chain in China. Renew Sustain Energy 39:356-369

[3] Haddad B, Liazid A, Ferreira P (2017) A multi-criteria approach to rank renewables for the Algerian electricity system. Renew Energy 107:462-472

[4] Teresa M, Laura GI, Isabel CG (2017) Analysis of the promotion of onshore wind energy in the EU: feed-in tariff or renewable portfolio standard. Renew Energy 111:256-264

[5] Christoforaki M, Theocharis T (2017) Sustainable siting of an offshore wind park a case in Chania, Crete. Renew Energy 109:624-633
[6] Atmaca E, Basar HB (2012) Evaluation of power plants in Turkey using analytic network process (ANP). Energy 44(1):555-563

[7] Xu X, Niu D, Qiu J (2016) Comprehensive evaluation of coordination development for regional power grid and renewable energy power supply based on improved matter element extension and TOPSIS method for sustainability. Sustainability $8(2): 1-17$

[8] Evans A, Strezov V, Evans TJ (2009) Assessment of sustainability indicators for renewable energy technologies. Renew Sustain Energy Rev 13(5):1082-1088

[9] Kaldellis JK, Zafirakis D (2011) The wind energy revolution: a short review of a long history. Renew Energy 36:1887-1901

[10] Jin TC, Zhou M, Li GY et al (2017) Universal generating function based probabilistic production simulation for wind power integrated power systems. J of Mod Power Syst Clean Energy 5(1):134-141

[11] Nikolaev A, Konidari P (2017) Development and assessment of renewable energy policy scenarios by 2030 for Bulgaria. Renew Energy 111:792-802

[12] Khishtandar S, Zandieh M, Dorri B (2017) A multi criteria decision making framework for sustainability assessment of bioenergy production technologies with hesitant fuzzy linguistic term sets: The case of Iran. Renew Sustain Energy Rev 77:1130-1145

[13] Dinmohammadi A, Shafiee M (2017) Determination of the most suitable technology transfer strategy for wind turbines using an integrated AHP-TOPSIS decision model. Energies 10(5):642-659

[14] Xiao W (2016) Application of Largrange functions for internal force calculation of statically indeterminate structure. Spat Struct 22(1):25-30

Jiahui WU received the B.E. degree in Control Engineering from Beijing University of Chemical Technology in 2011 and Ph.D. degree in the area of Power System Stability and Control at the School of Electrical Engineering, Xinjiang University in 2018. She currently works in Xinjiang University. Her research interests include power system stability and integration of the renewable resources.

Haiyun WANG received the B.E. degree in Department of Electrical Engineering of Xinjiang University in 1995 and the M.E. degree in the field of Electrical Engineering from Dalian University of Technology in 1996. She is the professor the Department of Electrical Engineering of Xinjiang University. Her research interests include the key components of large wind turbine and power system security and stability and its control and protection.

Weiqing WANG received the B.E. degree in Department of Electrical Engineering of Xinjiang University in 1983 and the M.E. degree in the field of Electrical Engineering from the Department of Electrical Engineering at Zhejiang University in 1990. He is the professor the Department of Electrical Engineering of Xinjiang University. His research interests include the detection technology of wind turbines and power system security and stability analysis.

Qiang ZHANG received the B.E. degree in Department of Electrical Engineering of Shandong Jiaotong University in 2011 and the M.E. degree in the field of Electrical Engineering from the Department of Electrical Engineering of Xinjiang University in 2013. His research interest includes stability and security of power system. 